\title{
Chromosomal evolution of Escherichia coli for the efficient production of lycopene
}

\author{
Yun-Yan Chen ${ }^{1}$, Hong-Jie Shen ${ }^{1}$, Yan-Yan Cui ${ }^{1}$, Shang-Guang Chen ${ }^{1}$, Zhi-Ming Weng ${ }^{1}$, Ming Zhao ${ }^{2 *}$ \\ and Jian-Zhong Liu ${ }^{1 *}$
}

\begin{abstract}
Background: Plasmid-based overexpression of genes has been the principal strategy for metabolic engineering. However, for biotechnological applications, plasmid-based expression systems are not suitable because of genetic instability, and the requirement for constant selective pressure to ensure plasmid maintenance.

Results: To overcome these drawbacks, we constructed an Escherichia coli lycopene production strain that does not carry a plasmid or an antibiotic marker. This was achieved using triclosan-induced chromosomal evolution, a high gene copy expression system. The engineered strain demonstrated high genetic stability in the absence of the selective agent during fermentation. The replacement of native appY promoter with a T5 promoter, and the deletion of the iclR gene in E. coli CBW 12241 further improved lycopene production. The resulting strain, E. coli CBW 12241(4iclR, $\mathrm{P}_{\mathrm{T} 5}$-app Y), produced lycopene at $33.43 \mathrm{mg}$ per gram of dry cell weight.

Conclusions: A lycopene hyper-producer E. coli strain that does not carry a plasmid or antibiotic marker was constructed using triclosan-induced chromosomal evolution. The methods detailed in this study can be used to engineer $E$. coli to produce other metabolites.
\end{abstract}

Keywords: Lycopene, Escherichia coli, Chemically induced chromosomal evolution, Metabolic engineering

\section{Background}

Carotenoids are a diverse class of $\mathrm{C}_{40}$ isoprenoids that have multiple physiological and nutritional functions in many organisms. Carotenoids have received considerable attention from the food industry, medicine and cosmetics because of their interesting pigment properties, and more importantly, their potential beneficial effects on human health. Lycopene is an effective antioxidant [1] and has beneficial biological and pharmaceutical activities, including anti-cancer [2], anti-inflammatory [3], and antioxidative activities [4]. Lycopene is widely used as a supplement in functional foods, animal feed, nutraceuticals, pharmaceuticals and as an additive in cosmetics.

Potential commercial applications mean that efficient biotechnological production of lycopene has become increasingly necessary, and a number of reports have

\footnotetext{
* Correspondence: zhaoming_shch@hotmail.com; Issljz@mail.sysu.edu.cn ${ }^{2}$ Medical Imaging Center, Cancer Center and State Key Laboratory of Oncology in South China, Sun Yat-Sen University, Guangzhou 510060, P. R. China

${ }^{1}$ Biotechnology Research Center and MOE Key Laboratory of Bioinorganic and Synthetic Chemistry, School of Life Science, Sun Yat-Sen University,
} Guangzhou 510275, P. R. China described its production using metabolic engineering [5-21]. However, all of these above studies focused on the deletion of undesirable genes and plasmid overexpression of key genes. Such plasmid-based expression systems have several drawbacks, including structural instability, segregational instability or allele segregation [22-24]. These plasmid instabilities cause genetic instability, which reduces the production of the compound of interest. Tyo et al. reported that plasmid-carrying strains lost poly-3-hydroxybutyrate (PHB) productivity after 40 generations with antibiotics [25]. Moreover, antibiotic resistance genes are the most commonly used markers for selecting and maintaining plasmids in hosts during cultivation. However, antibiotics are both costly and banned from food and pharmaceutical production processes. There is also a potential risk of the spread of antibiotic-resistant marker to other microbes in nature, leading to the rapid emergence of multidrug-resistant organisms (e.g., superbacteria) [26,27].

These drawbacks of using plasmids can be overcome by integration of genes into the chromosome. Recently, Tyo et al. developed a plasmid-free method for the over-

\section{Biomed Central}


production of metabolites that can achieve high copy numbers of the desired genes, termed chemically induced chromosomal evolution (CIChE) [25]. Genes of interest were inserted into chromosome of Escherichia coli by the $\lambda I n C h$ genomic integration method, and then evolved to the desired gene copy number by chemical induction. However, the $\lambda \mathrm{InCh}$ genomic integration protocol is complicated and time-consuming, because it contains three steps that involve two recombination steps. Chiang et al. modified the conditional-replication, integration, and modular plasmid system produced by Haldimann and Wanner [28], and developed a replicon-free and markerless method (RMM) for the chromosomal insertion of genes [26]. Genes of interest can be directly integrated into the bacterial attachment site of the E. coli chromosome as single copies, through transformation. However, the CIChE strains reported by Tyo et al. still have an antibiotic resistance marker (chloramphenicol resistance) [25]. To avoid the use of antibiotic resistance genes and antibiotics, Goh and Good developed a novel system using the widely used the biocide triclosan as the selective agent and the essential growth gene fabI of E. coli as the selective marker [27]. Thus, to overcome the drawbacks of $\mathrm{CIChE}$ as originally developed by Tyo et al., we developed a series of integration expression vectors, pXKF3T5b, for triclosan induction chromosomal evolution in our previous paper [29]. Using these vectors, genes of interest can be inserted into E. coli site-specifically by transformation using RMM. The gene copy number can then be evolved to the desired value by triclosan induction. In this study, we constructed a lycopene hyper-producer $E$. coli that does not carry plasmid or antibiotic marker, using the CIChE integration expression vector. To the best of our knowledge, this is the first report of metabolic engineering of an $E$. coli that does not carry a plasmid or antibiotic marker using a multiple gene expression system for lycopene production.

\section{Results and discussion}

\section{CIChE of E. coli for lycopene production}

To overcome the drawbacks of CIChE as originally devised by Tyo et al., we developed a series of integration expression vectors, pXKF3T5b, for triclosan induction chromosomal evolution in our previous paper [29]. Using these vectors, genes of interest can be inserted into $E$. coli site-specifically by transformation using RMM. The gene copy number can then be evolved to the desired value by triclosan induction. Thus, strains constructed using our CIChE integration expression vectors have no antibiotic resistance and are environmentally safe.

The CIChE integration expression vector containing the lycopene biosynthetic gene cluster (pP21KF3T5b-EIBipi) was transferred into E. coli BW25113 ( $\triangle$ gdhA $\triangle a c e E$, $\left.\mathrm{P}_{\mathrm{T} 5}-d x s\right)$ and then increasing triclosan concentration was used to induce CIChE. Figure 1 shows the results of lycopene production in CIChE strains resistant to different triclosan concentrations. Lycopene production in CIChE strains increases with increasing triclosan concentration during chromosomal evolution. The maximum lycopene production of $9.55 \pm 0.23 \mathrm{mg} / \mathrm{g}$ dry cell weight (DCW) was obtained by the CIChE strains resistant to $8 \mu \mathrm{M}$ triclosan cultured in 2YT medium. Figure 2 shows that the crtI gene copy number of the CIChE strains increases with triclosan concentration during chromosomal evolution. At a triclosan concentration of $8 \mu \mathrm{M}$, the copy number reached about 30 in the CIChE strains, which is the equivalent copy number of a medium to high copy plasmid. When the triclosan concentration was above $8 \mu \mathrm{M}$, the gene copy number still increased; however, the lycopene production of the CIChE strains did not increase. The results indicated that there is an optimal copy number of the crt genes for efficient production of lycopene. Thus, the recA gene of the CIChE strain that was resistant to $8 \mu \mathrm{M}$ triclosan was deleted to obtain E. coli CBW12241, in which homologous recombination, which could reduce the copy number, is inhibited. The $c r t$ gene number of the recA-deleted strain did not change (data not shown). The genetic stability was also assayed (Table 1). The level of lycopene production in E. coli CBW12241 remained constant after 30 rounds of subculturing without triclosan. However, the plasmid-bearing strain E. coli BW25113 ( $\Delta g d h A \Delta a c e E, \mathrm{P}_{\mathrm{T} 5}-d x s$, pBAD24WZM1) lost lycopene productivity sharply, whether cultured with antibiotics or not. With antibiotics, the level of lycopene production in the plasmid-bearing strain, E. coli BW25113 ( $\Delta g d h A \triangle a c e E, \mathrm{P}_{\mathrm{T} 5}-d x s$, pBAD24-WZM1), was only about $30 \%$ of that of the parent strain after 30 rounds of subculturing. Without antibiotics, the lycopene productivity of the plasmid-bearing strain E. coli BW25113

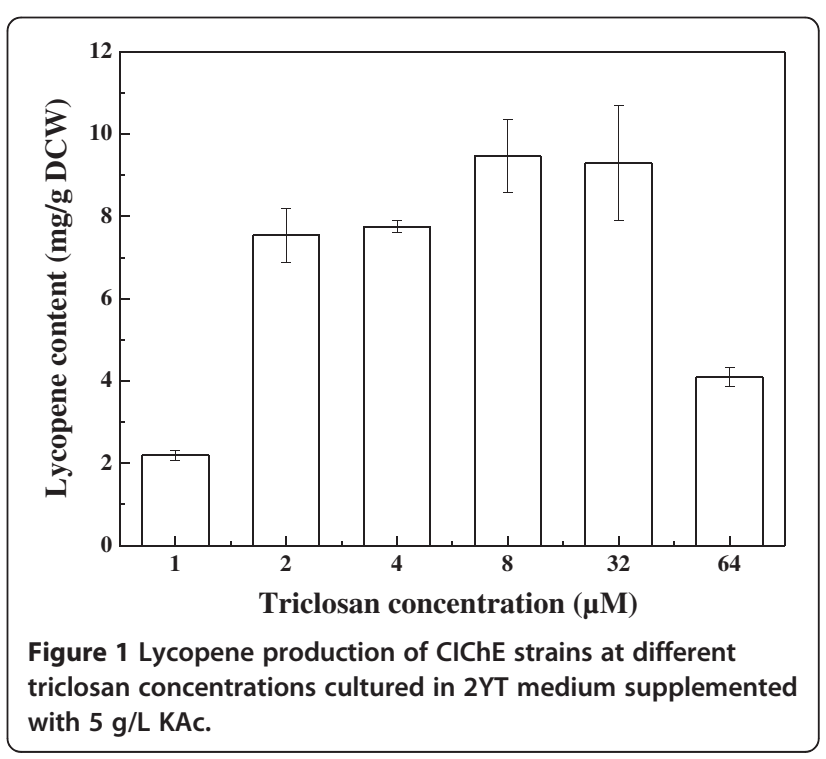




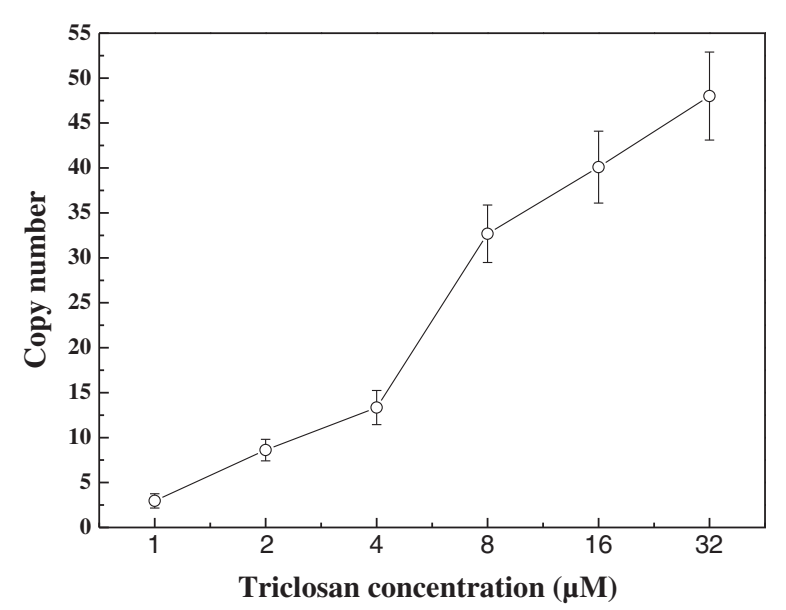

Figure 2 Copy number of the crtl gene in $\mathrm{ClChE}$ strains at different triclosan concentrations.

( $\left.\triangle g d h A \Delta a c e E, \mathrm{P}_{\mathrm{T} 5}-d x s, \mathrm{pBAD} 24-\mathrm{WZM} 1\right)$ dropped to zero after 30 rounds of subculturing. These results are consistent with previous reports wherein the gene copy number and $\mathrm{PHB}$ production of a CIChE strain remained constant after 40 rounds of subculturing [25]. They also found that PHB productivity of the plasmid-carrying strain cultured with antibiotics was completely lost after 40 generations. The loss of productivity in the plasmid system with antibiotics may be due to allele segregation. It is likely to occur regularly, despite antibiotic selection, particularly in subculturing experiments or in chemostats [25].

\section{Optimization of the lycopene synthetic pathway}

Overexpression of the idi, dxs, pck, pps, rpoS, appY, yjiD, $y c g W, w r b A$ and $a t p E$ genes are reported to improve lycopene production in E. coli $[8-19,21]$. Thus, the

Table 1 Genetic stability of the CIChE and the plasmidcarrying strain $^{\mathrm{a}}$

\begin{tabular}{|c|c|c|}
\hline Number of subculture & $\mathrm{OD}_{600}$ & $\begin{array}{l}\text { Specific lycopene } \\
\text { content (mg/gDCW) }\end{array}$ \\
\hline \multicolumn{3}{|l|}{ E. coli CBW12241 } \\
\hline 1 & $6.85 \pm 1.83$ & $28.57 \pm 0.50$ \\
\hline 5 & $5.59 \pm 0.31$ & $29.76 \pm 0.76$ \\
\hline 10 & $4.37 \pm 0.49$ & $31.05 \pm 1.11$ \\
\hline 15 & $4.47 \pm 0.37$ & $30.37 \pm 1.21$ \\
\hline 20 & $4.61 \pm 0.45$ & $30.95 \pm 1.21$ \\
\hline 25 & $4.39 \pm 0.39$ & $28.95 \pm 0.85$ \\
\hline 30 & $4.92 \pm 0.10$ & $30.53 \pm 1.53$ \\
\hline \multicolumn{3}{|c|}{ E. coli BW25113 (4gdhA4aceE, $\mathrm{P}_{\mathrm{T} 5}-d x s$, pBAD24-WZM1) } \\
\hline 1 & $4.29 \pm 0.51$ & $7.51 \pm 0.76$ \\
\hline 30, with Amp & $7.15 \pm 0.38$ & $2.24 \pm 0.46$ \\
\hline 30, without Amp & $8.51 \pm 0.45$ & 0 \\
\hline
\end{tabular}

effects of over-expression of these genes in E. coli CBW12241 on lycopene production were investigated. The results are presented in Table 2. Surprisingly, only the over-expression of app $Y$ slightly enhanced the specific lycopene content. This may reflect the different genetic backgrounds of the strains. In E. coli CBW12241, isopentenyl diphosphate isomerase is overexpressed by chromosomal evolution of ipiHPI. Thus, overexpression of the idi gene in E. coli CBW12241 was not beneficial to lycopene production. Zhao et al. [30] reported that the $d x s$ gene from Bacillus subtilis functioned more efficiently to enhance isoprene production in E. coli than the native $d x s$ gene. However, overexpression of the $d x s$ gene from Bacillus subtilis significantly inhibited lycopene production in E. coli CBW12241, possibly because the T5 promoter has replaced the native promoter of the $d x s$ gene in E. coli CBW12241.

To reduce the metabolic burden caused by the plasmid, the native promoter of the appY gene was replaced with the T5 promoter to obtain E. coli CBW12241 $\left(\mathrm{P}_{\mathrm{T} 5}\right.$-app $\left.Y\right)$. As shown in Table 3 , the replacement improved cell growth and lycopene concentration. Kang et al. used a shotgun approach and found that overexpression of the appY gene improved lycopene production [12]. The app $Y$ gene encodes a transcriptional activator of two regulator energy metabolism operons, hya and $c b d A B$-appA, which are induced by anaerobiosis. They reasoned that the app $Y$ gene might help rescue the strain from energy insufficiency caused by lower ubiquinone levels.

Table 2 Effect of plasmid-based overexpression of genes on lycopene production in the CIChE strain $E$. coli CBW12241*

\begin{tabular}{llll}
\hline Plasmid & OD $_{\mathbf{6 0 0}}$ & $\begin{array}{l}\text { Lycopene } \\
\text { concentration } \\
\text { (mg/L) }\end{array}$ & $\begin{array}{l}\text { Specific lycopene } \\
\text { content (mg/gDCW) }\end{array}$ \\
\hline pBAD24 & $9.54 \pm 0.73$ & $57.79 \pm 1.60$ & $19.01 \pm 1.64$ \\
\hline pBappY & $8.95 \pm 0.08$ & $57.75 \pm 0.49$ & $20.16 \pm 0.18$ \\
\hline pBidi & $10.20 \pm 0.22$ & $62.49 \pm 1.43$ & $19.15 \pm 0.66$ \\
\hline pBpck & $10.28 \pm 0.46$ & $58.87 \pm 2.34$ & $17.90 \pm 0.15$ \\
\hline pBpps & $10.51 \pm 0.57$ & $60.11 \pm 0.97$ & $17.91 \pm 1.29$ \\
\hline pBrpoS & $10.91 \pm 0.34$ & $60.17 \pm 1.54$ & $17.25 \pm 0.99$ \\
\hline pBycgW & $10.53 \pm 0.42$ & $60.43 \pm 0.92$ & $17.96 \pm 0.54$ \\
\hline pByjiD & $10.54 \pm 0.10$ & $58.29 \pm 0.34$ & $17.28 \pm 0.07$ \\
\hline pBdxs & $10.25 \pm 0.45$ & $62.02 \pm 1.66$ & $18.91 \pm 0.47$ \\
\hline pQE30 & $7.72 \pm 0.13$ & $52.92 \pm 1.53$ & $21.42 \pm 0.67$ \\
\hline pQwrbA & $13.76 \pm 0.47$ & $7.51 \pm 0.58$ & $1.71 \pm 0.13$ \\
\hline pQydeO & $13.19 \pm 0.17$ & $9.81 \pm 0.62$ & $2.33 \pm 0.15$ \\
\hline pQatpE & $9.73 \pm 0.17$ & $45.21 \pm 0.67$ & $14.53 \pm 0.06$ \\
\hline pQdxs & $11.49 \pm 0.31$ & $25.62 \pm 1.84$ & $6.97 \pm 0.64$ \\
\hline
\end{tabular}

$\overline{{ }^{a} \text { Cells were cultured in SBMSN medium supplemented with } 5 \mathrm{~g} / \mathrm{L} \mathrm{KAc} \text { without }}$ triclosan at $37^{\circ} \mathrm{C}$ for $48 \mathrm{~h}$. Data represent means of triplicate cultures \pm standard deviation. 
Table 3 Lycopene production and biomass yield of recombinant strains ${ }^{\mathrm{a}}$

\begin{tabular}{llll}
\hline Strain & OD $_{600}$ & $\begin{array}{l}\text { Lycopene } \\
\text { concentration } \\
\text { (mg/L) }\end{array}$ & $\begin{array}{l}\text { Specific } \\
\text { lycopene content } \\
\text { (mg/gDCW) }\end{array}$ \\
\hline E. coli CBW12241 & $5.87 \pm 0.67$ & $54.15 \pm 3.44$ & $28.97 \pm 0.67$ \\
\hline $\begin{array}{l}\text { E. coli CBW12241 } \\
\left(\mathrm{P}_{\mathrm{T5}} \text {-appY) }\right.\end{array}$ & $8.56 \pm 1.50$ & $79.17 \pm 7.20$ & $29.59 \pm 0.81$ \\
\hline $\begin{array}{l}\text { E. coli CBW12241 } \\
(\Delta \mathrm{iclR})\end{array}$ & $5.38 \pm 0.16$ & $51.32 \pm 2.86$. & $29.82 \pm 0.78$ \\
\hline $\begin{array}{l}\text { E. coli CBW12241 } \\
\left(\triangle \mathrm{iClR}, \mathrm{P}_{\mathrm{T5}} \text {-appY) }\right.\end{array}$ & $7.49 \pm 1.58$ & $77.85 \pm 1.42$ & $33.43 \pm 0.81$ \\
\hline E. coli CBW12251 & $6.90 \pm 1.01$ & $70.07 \pm 1.44$ & $31.73 \pm 0.48$ \\
\hline
\end{tabular}

${ }^{a}$ Cells were cultured in SBMSN medium supplemented with $5 \mathrm{~g} / \mathrm{L} \mathrm{KAc}$ without triclosan at $37^{\circ} \mathrm{C}$ for $48 \mathrm{~h}$. Data represent means of triplicate cultures \pm standard deviation.

A comparative transcriptome and proteome analysis demonstrated that the deletion of the transcriptional repressor $i c l R$ of the glyoxylate pathway increased lycopene production [31]. Thus, we deleted the $i c l R$ gene and examined lycopene production. The deletion of the $i c l R$ gene in E. coli CBW12241 caused a slight inhibition of growth and did not affect the specific lycopene content. The deletion of the $i c l R$ gene in the promoter replacement strain, E. coli $\mathrm{CBW} 12241$ ( $\mathrm{P}_{\mathrm{T} 5}$-appY), slightly improved specific lycopene content, from $28.97 \pm 0.67 \mathrm{mg} / \mathrm{g}$ DCW to $33.43 \pm$ $0.81 \mathrm{mg} / \mathrm{gDCW}$, and improved the lycopene concentration from $54.15 \pm 3.44 \mathrm{mg} / \mathrm{L}$ to $77.85 \pm 1.42 \mathrm{mg} / \mathrm{L}$ (Table 3). In the $i c l R$ gene knockout strain, the glyoxylate pathway is constitutively active [32]. Furthermore, there are other examples of metabolic engineering involving deleting $i \mathrm{cl} R$ to increase productions of compounds. Sanchez et al. successfully knocked out $i c l R$ to boost the glyoxylate pathway flux for succinate overproduction [33]. Lee et al. observed aceBA upregulation in the threonine-overproducing E. coli, and when iclR deleted, a 30\% higher threonine production was recorded [34].

Many reports have been published about lycopene production using recombinant E. coli [5-21]. However, these strains contain plasmids, which can cause genetic instability and can have a negative environmental impact. Chiang et al. [26] constructed a lycopene hyper-producer $E$. coli strain that did not carry the replicon or a selective marker using RMM. However, RMM is a single gene copy expression system. Tyo et al. [25] constructed a lycopene producer $E$. coli using CIChE, a plasmid-free, high gene copy expression system. However, this strain still contained a chloramphenicol resistance marker. In the present study, we engineered a lycopene producer $E$. coli that does not carry a plasmid or an antibiotic marker. The CIChE strain only contains the $f a b I$ gene, which is essential for the growth of $E$. coli. The strain does not present the safety problems associated with antibiotic resistance genes in plasmids. Moreover, the strain does not require the presence of the resistance compound (triclosan) during the fermentation process. To the best of our knowledge, this is the first report of engineering an E. coli that does not carry a plasmid or antibiotic marker using a high gene copy expression system.

The maximum specific lycopene content $(33.43 \mathrm{mg} / \mathrm{g}$ DCW) of E. coli CBW12241 ( $\Delta i c l R, \mathrm{P}_{\mathrm{T} 5-\text { app Y) was higher }}$ than that of the CIChE strain reported by Tyo et al. (about $11 \mathrm{mg} / \mathrm{gDCW}$ ) [25]. The value was also higher than other plasmid-carrying strains, which achieved $22 \mathrm{mg} / \mathrm{g}$ DCW [21], $18 \mathrm{mg} / \mathrm{g}$ DCW [6] or $32 \mathrm{mg} / \mathrm{g}$ DCW produced by the engineered $E$. coli containing heterologous lycopene and mevalonate pathways [35]. However, the yield is slightly lower than that reported by Chiang et al. (38.5 mg/g DCW) [26]. In their study, the RMM strain $E$. coli BL21-CrtD1K has an additional chromosomal copy of $d x s$ fused to the T7 promoter. However, plasmid-based overexpression of the $d x s$ gene in the CIChE strain did not further enhance lycopene production. Moreover, $E$. coli CBW12251, containing an additional chromosomal copy of the $d x s$ gene, produced lycopene at $31.73 \pm$ $0.48 \mathrm{mg} / \mathrm{gDCW}$, which was lower than E. coli CBW12241 ( $\triangle i c l R, \mathrm{P}_{\mathrm{T} 5}$-appY) (Table 3).

Although the yield of our engineered E. coli harboring only a heterologous lycopene pathway achieved the advanced levels quoted in the literature, many papers have reported that the introduction of a heterologous mevalonate pathway improved production of isoprenoids such as lycopene $[16,17,20,35], \mathrm{CoQ}_{10}[36], \alpha$-farnesene [37], terpenoid [38], taxol [39] and amorphadiene [40]. Thus, integration of a heterologous mevalonate pathway into the chromosome of the engineered $E$. coli CBW12241 ( $\Delta i c l R, \mathrm{P}_{\mathrm{T} 5}$-appY) may further improve lycopene production.

\section{Conclusions}

We constructed a lycopene producer $E$. coli strain that does not carry a plasmid or antibiotic marker using CIChE, replacement of a promoter as well as knockout of a gene. No resistance compound was required during the fermentation process using this strain. This is the first report of engineering an E. coli that lacks a plasmid and an antibiotic marker using a high gene copy expression system. The engineered strain remained stable, as determined by its lycopene production, after 30 sequential transfers.

\section{Methods}

\section{Strains, primers and plasmids}

The strains and plasmids used in this study are listed in Table 4. E. coli DH5 $\alpha$ was used for plasmid construction. E. coli BW2511 ( $\left.\triangle a c e F \Delta g d h A, \mathrm{P}_{\mathrm{T} 5}-d x s\right)$ [19] was used as the parent strain for chromosomal integration. The primers used in this study are listed in Table 5. 


\section{Chemically induced chromosomal evolution}

The crtE, crtI, crtB and ipi gene cluster was cut from pBAD24-WZM1 [19] using restriction enzymes ClaI and HindIII and treated with Primestar HS DNA polymerase (TaKaRa, China) and digested with EcoRI. The resulting gene cluster was cloned into the EcoRI/BamHI sites of pP21KF3T5b [29] to obtain pP21KF3T5b-crtEIBipi. The resulting integration vector was inserted into the bacterial attachment (attB) site of E. coli using a helper plasmid, pAH121, expressing the phage integrase, by direct transformation, as described by Chiang et al. [26]. The general procedure for using the integration vector is illustrated in Figure 3. In brief, strains containing the helper plasmid pAH121 were first cultured in super optimal broth (SOB) medium with $100 \mu \mathrm{g} / \mathrm{mL}$ of ampicillin (Amp) at $30^{\circ} \mathrm{C}$ to an optical density at $600 \mathrm{~nm}$ of approximately 0.6. The

Table 4 List of bacterial strains and plasmids used in this study

\begin{tabular}{|c|c|c|}
\hline Strain or plasmid & Description $^{a}$ & $\begin{array}{l}\text { Source or } \\
\text { reference }\end{array}$ \\
\hline \multicolumn{3}{|l|}{ Strains } \\
\hline E. coli DH5a & supE44 $\triangle$ (lacZYA-argF) U169 (Ф80lacZ $\Delta M 15)$ hsdR17 recA endA1 gyrA96 thi-1 relA1 & Invitrogen \\
\hline E. coli BW25113 & lacla $\mathrm{rrnB}_{\mathrm{T} 14} \Delta \mathrm{lac}_{\mathrm{W} 16}$ hsdR514 $\triangle a \mathrm{araBAD} \mathrm{AH}_{\mathrm{AH3}} \Delta \mathrm{rhaBAD_{ \textrm {LD } 7 8 }}$ & 42 \\
\hline $\begin{array}{l}\text { E. coli BW25113 } \\
\left(\Delta g d h A \Delta a c e E, \mathrm{P}_{\mathrm{T} 5}-d \times s\right)\end{array}$ & E. coli BW25113, $\Delta g d h A, \Delta a c e E$, replacement of native promoter of the $d x s$ gene with T5 promoter & 19 \\
\hline E. coli CBW12241 & 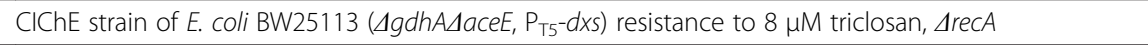 & This study \\
\hline E. coli CBW12241 ( $\mathrm{P}_{\mathrm{T} 5}$-appY) & E. coli CBW12241, replacement of native promoter of the appY gene with T5 promoter & This study \\
\hline E. coli CBW12241 ( $\triangle i \mathrm{il} / R)$ & E. coli CBW12241, $\Delta i c / R$ & This study \\
\hline $\begin{array}{l}\text { E. coli CBW12241 ( } \triangle \text { iclR, } \mathrm{P}_{\mathrm{T}^{-}} \\
\text {appY) }\end{array}$ & 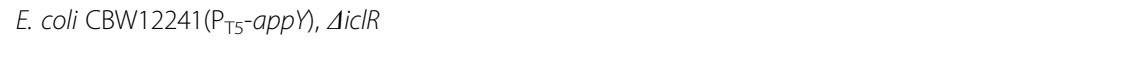 & This study \\
\hline E. coli CBW12251 & $\begin{array}{l}\text { E. coli CBW12241 ( } \triangle \text { iclR, } \mathrm{P}_{\mathrm{T} 5} \text {-app Y) with an additional chromosomal copy of } d x s \text { under the control of } \\
\text { T5 promoter }\end{array}$ & \\
\hline \multicolumn{3}{|l|}{ Plasmid } \\
\hline pP21KF3T5b & CIChE integration expression vector, $\mathrm{Kan}^{r}$ & 29 \\
\hline pP21KF3T5b-crtEBlipi & $\begin{array}{l}\text { pP21KF3T5b derivative containing crtE, crtB and crtl gene from Pantoea agglomerans and ipiHPI from } \\
\text { Haematococcus pluvialis, Kan' }\end{array}$ & This study \\
\hline pAH121 & Helper plasmid expressing phage P21 Int, Amp ${ }^{r}$ & 28 \\
\hline pBAD24-WZM1 & $\begin{array}{l}\text { pBAD24 derivative containing } c r t E, c r t B \text { and } c r t l \text { gene from Pantoea agglomerans and ipiHPI from } \\
\text { Haematococcus pluvialis, Amp }\end{array}$ & 19 \\
\hline pSIM6 & pSC101 replicon $^{\text {ts }} \mathrm{P}_{\mathrm{L}}$-gam-bet-exo c/857, Ampr & 43 \\
\hline pKD4 & oriRy, FRT::kan::FRT template plasmid, $\mathrm{Kan}^{r}, \mathrm{Amp}^{r}$ & 42 \\
\hline $\mathrm{pCP} 20$ & pSC101 replicon ${ }^{\text {ts }} \mathrm{Flp}(\lambda \mathrm{Rp}) \mathrm{c} / 857, \mathrm{Cm}^{\mathrm{r}}, \mathrm{Amp}^{\mathrm{r}}$ & 42 \\
\hline pBAD24 & pMB1 ori, $\mathrm{P}_{\mathrm{BAD}} \mathrm{L}$-arabinose inducible, $\mathrm{Amp}^{r}$ & 41 \\
\hline pBappY & pBAD24 derivative containing the appY gene from E. coli, Amp ${ }^{r}$ & This study \\
\hline pBidi & pBAD24 derivative containing the idi gene from E. coli, Ampr & This study \\
\hline pBpck & pBAD24 derivative containing the pck gene from E. coli, Amp ${ }^{r}$ & This study \\
\hline pBpps & pBAD24 derivative containing the pps gene from E. coli, Ampr & This study \\
\hline pBrpos & pBAD24 derivative containing the rpoS gene from E. coli, Ampr & This study \\
\hline pBycgW & pBAD24 derivative containing the $y c g W$ gene from E. coli, Amp ${ }^{r}$ & This study \\
\hline pByjiD & pBAD24 derivative containing the yjiD gene from E. coli, Amp ${ }^{r}$ & This study \\
\hline pQE30 & ColE1 ori, $\mathrm{P}_{\mathrm{T} 5}$ IPTG inducible, Ampr & Qiagen \\
\hline pQEwrbA & pQE30 derivative containing the wrbA gene from E. coli, Amp ${ }^{r}$ & This study \\
\hline pQydeO & pQE30 derivative containing the $y d e O$ gene from E. coli, Ampr & This study \\
\hline pQatpE & pQE30 derivative containing the atpE gene from E. coli, Ampr & This study \\
\hline pQdxs & pQE30 derivative containing the $d x s$ gene from Bacillus subtilis, Amp ${ }^{r}$ & This study \\
\hline
\end{tabular}


cells were made electrocompetent and transformed with the integration vector pP21KF3T5b-crtEIBipi. Following electroporation, the cells were suspended in SOB plus glucose medium without Ampicillin, incubated at $37^{\circ} \mathrm{C}$ for $1 \mathrm{~h}$ and at $42^{\circ} \mathrm{C}$ for $30 \mathrm{~min}$, and then spread onto Luria-Bertani (LB) agar plates containing $25 \mu \mathrm{g} / \mathrm{mL}$ of kanamycin (Kan) and incubated overnight at $37^{\circ} \mathrm{C}$. Colonies were verified by colony PCR using primer sets BLP1 and CGA, or BLP4 and CGB (Table 5). Positive colonies were cultured in $5 \mathrm{~mL} \mathrm{LB}$ medium with $25 \mu \mathrm{g} / \mathrm{mL}$ kanamycin at $42^{\circ} \mathrm{C}$ overnight and then spread onto an $\mathrm{LB}$ medium with Kan agar plate at $37^{\circ} \mathrm{C}$ overnight. Stable integration was scored by antibiotic resistance (conferring Kan resistance) and loss of the helper plasmid (conferring Amp sensitivity), as well as by colony PCR using primer sets BLP1 and CGA, or BLP4 and CGB (Table 5). To eliminate the region containing the selective marker (Kan resistance) and the replication origin, the resulting integrants bearing the inserted DNA were transformed with pCP20 expressing FLP recombinase [23]. Colonies only resistant to triclosan were verified by colony PCR using primer sets BLP1 and CGA, or BLP4 and CGB.

CIChE of the above construct was carried out by subculturing the resulting strains in $5 \mathrm{~mL} \mathrm{SOB}$ medium with increasing concentrations of triclosan, in $15 \mathrm{~mL}$ culture tubes, as described by Tyo et al. [25]. The strains were grown to stationary phase in $1 \mu \mathrm{M}$ triclosan. Fifty milliliters of the culture was subcultured into a new culture tube. In the new tube, the triclosan concentration was doubled from $2 \mu \mathrm{M}$ to $64 \mu \mathrm{M}$ and allowed to grow to stationary phase. The process was repeated until the desired concentration was reached. The recA gene of the $\mathrm{CIChE}$ strain was then deleted (see below).

\section{Construction of the plasmid}

The appY, idi, pck, pps, rpoS, $y c g W$ and $y j i D$ genes were amplified from E. coli genomic DNA using the primers shown in Table 5, and ligated into pBAD24 [41], respectively. The $w r b A, y d e O$ and atpE genes were amplified from genomic DNA of $E$. coli using the primers shown in Table 5 and ligated into pQE30, respectively. The $d x s$ gene was amplified from genomic DNA of B. subtilis ATCC 6633 using primers dxsF and dxsR (Table 5) and ligated into $\mathrm{pQE30}$ (Qiagen).

\section{Knockout of genes}

Gene knockouts and replacement of the native promoter of the appY gene with the T5 promoter were carried out by PCR product recombination [42] using the pSIM6 plasmid [43] expressing the lambda red recombination system and pKD4 [42] as the template for PCR. Gene knockouts were verified using colony PCR using the appropriate primers (Table 5 ).
Table 5 Primers used in this study

\begin{tabular}{|c|c|}
\hline Primers & Sequence and purpose ${ }^{a}$ \\
\hline BLP1 & $\begin{array}{l}5^{\prime} \text { - ATCGCCTGTATGAACCTG -3', Diagnostic PCR in attP P21 } \\
\text { integration }\end{array}$ \\
\hline BLP4 & $\begin{array}{l}5^{\prime} \text { - TAGAACTACCACCTGACC }-3 \text { ', Diagnostic PCR in attP P21 } \\
\text { integration }\end{array}$ \\
\hline$\overline{\mathrm{AHP} 2}$ & $\begin{array}{l}5^{\prime} \text { - ACACTTAACGGCTGACATGG -3', Diagnostic PCR in attP P21 } \\
\text { integration }\end{array}$ \\
\hline AHP3 & $\begin{array}{l}5^{\prime} \text { - AACGAGTATCGAGATGGCAC -3', Diagnostic PCR in attP } P_{P 21} \\
\text { integration }\end{array}$ \\
\hline CGA & $\begin{array}{l}\text { 5'- TCAAGAATCTGGTGACCGAGGAG -3', Diagnostic PCR in } \\
\text { attP P21 integration }\end{array}$ \\
\hline CGB & $\begin{array}{l}5^{\prime} \text { - ACGCCGCTTCAATGACGCTG -3', Diagnostic PCR in attP } P_{\mathrm{P} 21} \\
\text { integration }\end{array}$ \\
\hline$\underline{\text { VCA1 }}$ & GTCGTCAGGCTACTGCGTATG. Diagnostic PCR in recA deletion \\
\hline VCA2 & CACGATCCAACAGGCGAG. Diagnostic PCR in recA deletion \\
\hline NDF & 5'- TGGTAATAATGGCTTCGTCTG $-3^{\prime}$, qPCR for the $\min D$ gene \\
\hline NDR & 5'- GCGATAAAGATGCCCTCAC -3', qPCR for the minD gene \\
\hline QCF & 5'-CCAGGAGGGATATTTGC -3', qPCR for the crtl gene \\
\hline$\overline{Q C R}$ & 5'- CAGGGAGTGGAACGAGAAG -3', qPCR for the crtl gene \\
\hline wrbAR & 5'- CGGTCGACGCGTATCCTCCTGTTGAAGATTAG CCGTT - $3^{\prime}$ \\
\hline yedeOF & 5'- GCGTCGACAGGAGAGATAAAATGTCGCTCGT TTGTTCT -3' \\
\hline ydeOR & 5'- GGTCTCTGCAGTCAAATAGCTAAAGCATTCATCGT -3' \\
\hline atpEF & 5'- GAGAGCTCAGGAGGACTGTCATGGAAAACCTGAAT -3' \\
\hline atpER & 5'- CGGGGTACCTAAATAAAAGCAACGCTTACTACGC - -3' \\
\hline$d x s F$ & $\begin{array}{l}\text { 5'-CTGGGATCCAGGAGATCCGCTATGGATCTTITATCAA } \\
\text { TACAGGAC-3' }\end{array}$ \\
\hline $\mathrm{dxsR}$ & 5'- CCGGGTACCGCTGTCATGATCCAATTCCTITATGT -3' \\
\hline idiF & 5'-GAGGTACCAGGAGTTGTTCGATGTCCAACAATG-3' \\
\hline idiR & 5'-GGCTCTAGATTATTTAAGCTGGGTAAATGCAG-3' \\
\hline appYF & 5'-GCCTGCAGAGGAGGTGCAAGATGGATTATGT-3' \\
\hline appYR & 5'-CCGCATGCTTATCAGTCAATTGTTTTG-3' \\
\hline$\overline{p c k F}$ & 5'-GGAATTCTCAATGCGCGTTAACAATGGTT-3' \\
\hline pckR & 5'-CTCCCATGGTTACAGTTTCGGACCAGCC-3' \\
\hline ppsF & 5'-GAGGTACCAGGAGTTGTTCGATGTCCAACAATG-3' \\
\hline $\mathrm{ppsR}$ & 5'-CGTCCCGGGTTATTTCTTCAGTTCAGCCAGG-3' \\
\hline rpoSF & 5'-GCCTCTAGAAGGAGCCACCTTATGAGTCAGAATAC-3' \\
\hline rpoSR & 5'-GGTCGACTTACTCGCGGAACAGCGCTT-3' \\
\hline ycgWF & 5'-CGGCATGCAGGAGATAACAAATGAAGTGGATAGT-3' \\
\hline ycgWR & 5'-GCCAAGCTTTAGCATATCGAGCATATTT-3' \\
\hline yjiDF & 5'-GGTCGACAGGAGGCGCAAAATGATGCGACAAT-3' \\
\hline YJIDR & 5'-GGCTGCAGTTAGCTGACATTCTCCAGCG-3' \\
\hline APFP & $\begin{array}{l}\text { 5'- CTCCGTATAGAGTTCCATCGT -3', Diagnostic PCR in the } \\
\text { replacement of appY promoter }\end{array}$ \\
\hline APRP & $\begin{array}{l}\text { 5'- GCCACATTTCTGGGCTACGAC -3', Diagnostic PCR in the } \\
\text { replacement of appY promoter }\end{array}$ \\
\hline IKFP & $\begin{array}{l}5^{\prime} \text { - TGTTTATCAAGAGTGTCTGAGCGT }-3{ }^{\prime} \text {, Diagnostic PCR in the } \\
\text { deletion of the icIR gene }\end{array}$ \\
\hline 1 & $\begin{array}{l}\text { 5'- CGTTITCACCGCAAATACCG -3', Diagnostic PCR in the } \\
\text { deletion of the icIR gene }\end{array}$ \\
\hline
\end{tabular}

a Restriction enzyme sites are underlined. 


\section{Quantitative PCR (qPCR) measurement of gene copy number}

Gene copy numbers were measured by qPCR on genomic DNA isolated from the appropriate CIChE strains. qPCR was performed with an iCycler iQ5 Real Time PCR system (Bio-Rad Laboratories, USA) using the SYBR Premix Ex Taq II (TaKaRa, China), following the manufacturer's protocol. PCR conditions were as follows: $30 \mathrm{~s}$ at $95^{\circ} \mathrm{C} ; 40$ cycles of at $95^{\circ} \mathrm{C}$ for $5 \mathrm{~s}, 60^{\circ} \mathrm{C}$ for $30 \mathrm{~s}$, and $95^{\circ} \mathrm{C}$ for $60 \mathrm{~s}$; followed by melting curve analysis. The copy numbers of the crtI gene were detected and compared to the copy number of $\min D$, a nearby native gene in the chromosome. The primers QCF and QCR (Table 5) were used to measure the copy number of crtI. The primers NDF and NDR (Table 5) were used to measure the copy number of $\min D$.

\section{Lycopene production}

For lycopene production, $5 \mathrm{~mL}$ of LB medium supplement with $5 \mathrm{~g} / \mathrm{L}$ KAc was used for overnight precultivation of $E$. coli in a falcon tube at $37^{\circ} \mathrm{C}$. The main cultures were in 2YT medium or SBMSN medium supplemented with $5 \mathrm{~g} / \mathrm{L}$ KAc. SBMSN medium (pH7.0) contains $(\mathrm{g} / \mathrm{L})$ : peptone 12 , yeast extract $24, \mathrm{KH}_{2} \mathrm{PO}_{4}$ 1.7, $\mathrm{K}_{2} \mathrm{HPO}_{4} 11.42, \mathrm{MgCl}_{2} \cdot 6 \mathrm{H}_{2} \mathrm{O} 1$, ammonium oxalate 1.42, Tween-80 2. The main cultures were inoculated with a starting $\mathrm{OD}_{600}$ of 0.1 and incubated at $37^{\circ} \mathrm{C}$ for $24 \mathrm{~h}$ in a rotary shaking incubator at $150 \mathrm{rpm}$. Cell growth was measured by optical density at $600 \mathrm{~nm}$ and converted into DCW $(\mathrm{g} / \mathrm{L})$ using a standard curve.

\section{Extraction and measurement of lycopene}

The lycopene content of recombinant E. coli strains was quantified as previously reported [5]. Two hundred fifty microliters of $E$. coli cells were harvested by centrifugation at $12000 \mathrm{rpm}$ for $5 \mathrm{~min}$. The cell pellet was washed with water and then extracted in $1 \mathrm{~mL}$ of acetone at $55^{\circ} \mathrm{C}$ for $15 \mathrm{~min}$ with intermittent vortexing. The mixture was then centrifuged at $12000 \mathrm{rpm}$ for $10 \mathrm{~min}$, and the acetone supernatant was transferred to a new tube. The absorbance of the resulting extract was measured at $474 \mathrm{~nm}$ and converted to lycopene concentration

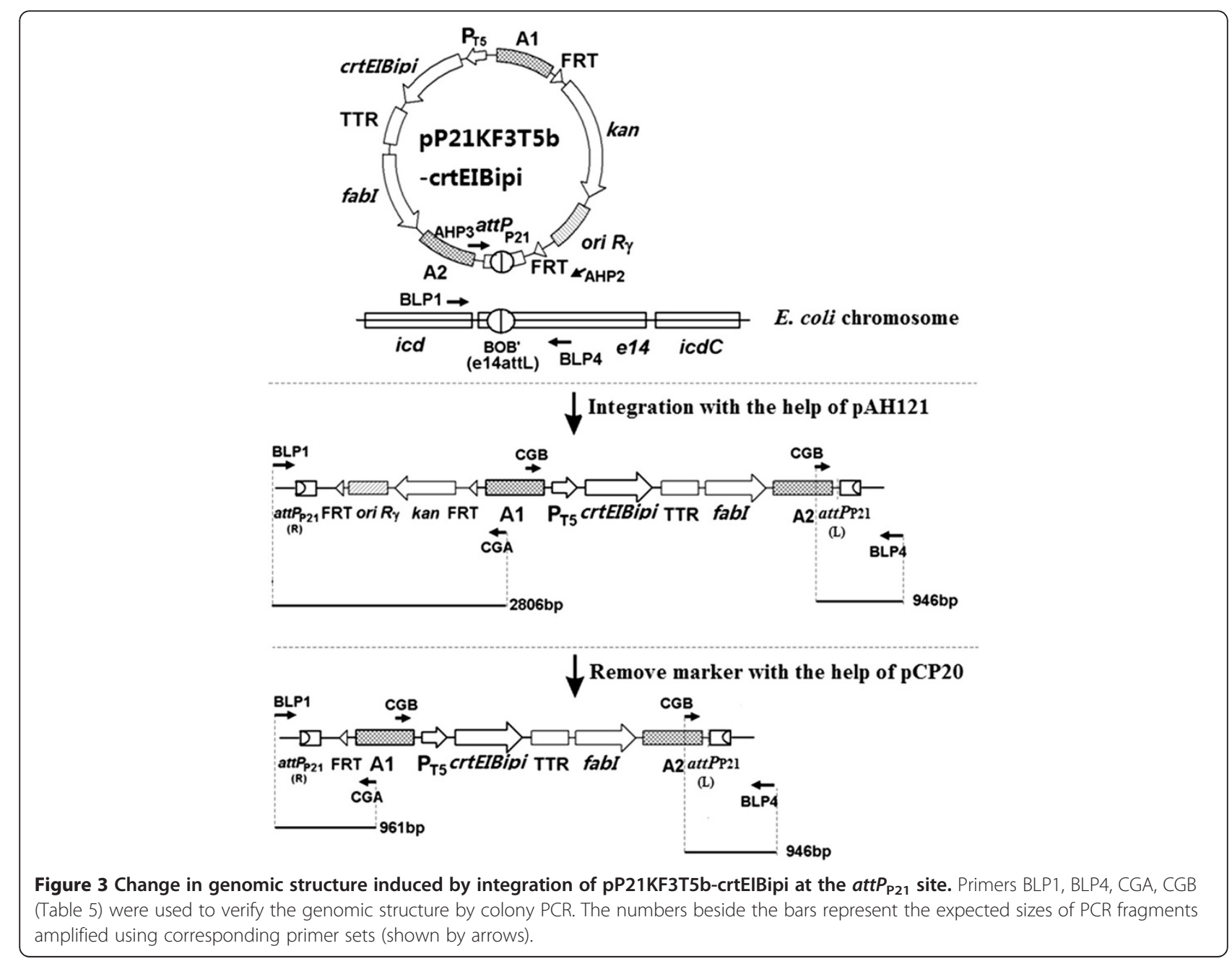


$(\mu \mathrm{g} / \mathrm{mL})$ using a standard curve obtained using commercial lycopene (Sigma).

\section{Statistical analysis}

All experiments were conducted in triplicate, and data were averaged and presented as the mean \pm standard deviation. One-way analysis of variance followed by Tukey's test was used to determine significant differences using the OriginPro (version 7.5) package. Statistical significance was defined as $p<0.05$.

\section{Competing interests}

The authors declare that they have no competing interests.

\section{Authors' contributions}

YY C carried out most of the experiments. HJ S constructed E. coli CBW12251 and investigated the effect of the $d x s$ gene. YY C constructed the integration expression vectors. SG C carried out fermentation experiments. ZM W constructed expression vectors for some of the genes. M Z guided the project. JZ $L$ developed the concept and designed the method, led the project and drafted the manuscript. All authors read and approved the final manuscript.

\section{Acknowledgments}

We are grateful to both the National Natural Science Foundation of China (Grant No. 30970089, 20876181, 21276289) and the Natural Science Foundation of Guangdong Province (No. 9351027501000003 ,

S2011010001396) for their financial support.

Received: 26 August 2012 Accepted: 24 January 2013

Published: 28 January 2013

\section{References}

1. Sies H, Stahl W: Lycopene: antioxidant and biological effects and its bioavailability in the human. Proc Soc Exp Biol Med 1998, 218:121-124.

2. Giovannucci E: A review of epidemiologic studies of tomatoes, lycopene, and prostate cancer. Exp Biol Med (Maywood) 2002, 227:852-859.

3. Bignotto L, Rocha J, Sepodes B, Eduardo-Figueira M, Pinto R, Chaud M, de Carvalho J, Moreno H JR, Mota-Filipe H: Anti-inflammatory effect of lycopene on carrageenan-induced paw oedema and hepatic ischaemiareperfusion in the rat. Br J Nutr 2009, 102:126-133.

4. Erdman JW Jr, Ford NA, Lindshield BL: Are the health attributes of lycopene related to its antioxidant function? Arch Biochem Biophys 2009, 483:229-235.

5. Alper H, Jin YS, Moxley JF, Stephanopoulos G: Identifying gene targets for the metabolic engineering of lycopene biosynthesis in Escherichia coli. Metab Eng 2005, 7:155-164.

6. Alper H, Miyaoku K, Moxley JF, Stephanopoulos G: Construction of lycopene-overproduction E. coli strains by combining systematic and combinatorial gene knockout targets. Nat Biotechnol 2005, 23:612-616.

7. Alper H, Stephanopoulos G: Uncovering the gene knockout landscape for improved lycopene production in E. coli. Appl Microbiol Biotechnol 2008, 78:801-810

8. Choi HS, Lee SY, Kim TY, Woo HM: In Silico identification of gene amplification targets for improvement of lycopene production. Appl Environ Microbiol 2010, 76:3097-3105.

9. Farmer WR, Liao JC: Improving lycopene production in Escherichia coli by engineering metabolic control. Nat Biotechnol 2000, 18:533-537.

10. Farmer WR, Liao JC: Precursor balancing for metabolic engineering of lycopene production in Escherichia coli. Biotechnol Prog 2001, 17:57-61.

11. Jin YS, Stephanopoulos G: Multi-dimensional gene target search for improving lycopene biosynthesis in Escherichia coli. Metab Eng 2007, 9:337-347.

12. Kang MJ, Lee YM, Yoon SH, Kim JH, Ock SW, Jung KH, Shin YC, Keasling JD, Kim SW: Identification of genes affecting lycopene accumulation in Escherichia coli using a shot-gun method. Biotechnol Bioeng 2005, 91:636-642.
13. Kang MJ, Yoon SH, Lee YM, Lee SH, Kim JE, Jung KH, Shin YC, Kim SW: Enhancement of lycopene production Escherichia coli by optimization of the lycopene synthetic pathway. J Microbiol Biotechnol 2005, 15:880-886.

14. Kim SW, Keasling JD: Metabolic engineering of the nonmevalonate isopentenyl diphosphate synthesis pathway in Escherichia coli enhances lycopene production. Biotechnol Bioeng 2001, 72:408-415.

15. Kim SW, Kim JB, Ryu JM, Jung JK, Kim JH: High-level production of lycopene in metabolically engineered E. coli. Process Biochem 2009, 44:899-905

16. Rad SA, Zahiri HS, Noghabi KA, Rajaei S, Heidari R, Mojallali L: Type 2 IDI performs better than type 1 for improving lycopene production in metabolically engineered E. coli strains. World J Microbiol Biotechnol 2012, 28:313-321.

17. Rodríguez-Villalón A, Pèrez-Gil J, Rodríguez-Concepción M: Carotenoid accumulation in bacteria with enhanced supply of isoprenoid precursors by upregulation of exogenous or endogenous pathways. J Biotechnol 2008, 135:78-84.

18. Wang CW, Oh MK, Liao JC: Directed evolution of metabolically engineered Escherichia coli for carotenoid production. Biotechnol Prog 2000, 16:922-926.

19. Weng ZM, Wang Y, Liu JZ: Overproduction of lycopene by metabolic engineering Escherichia coli. Bioprocess 2012, 2:51-57. doi:10.4236/bp. 2012.22009.

20. Yoon SH, Lee YM, Kim JE, Lee SH, Lee JH, Kim JY, Jung KH, Shin YC, Keasling JD, Kim SW: Enhanced lycopene production in Escherichia coli engineered to synthesize isopentenyl diphosphate and dimethylallyl diphosphate from mevalonate. Biotechnol Bioeng 2006, 94:1025-1032.

21. Yuan LZ, Rouvière PE, LaRossa RA, Suh W: Chromosomal promoter replacement of the isoprenoid pathway for enhancing carotenoid production in E. coli. Metab Eng 2006, 8:79-90.

22. Bentley WE, Mirjalili N, Andersen DC, Davis RH, Kompala DS: Plasmidencoded protein: the principal factor in the metabolic burden associated with recombinant bacteria. Biotechnol Bioeng 1990, 35:668-681.

23. Noack D, Roth M, Geuther R, Muller G, Undisz K, Hoffmeier C, Gaspar S: Maintenance and genetic stability of vector plasmids PBR322 and pBR325 in Escherichia coli K12 strains grown in a chemostat. Mol Gen Genet 1981, 184:121-124.

24. O'Connor M, Peifer M, Bender W: Construction of large DNA segments in Escherichia coli. Science 1989, 244:1307-1312.

25. Tyo KEJ, Ajikumar PK, Stephanopoulos G: Stabilized gene duplication enables long-term selection-free heterologous pathway expression. Nat Biotechnol 2009, 27:760-765.

26. Chiang C-J, Chen PT, Chao YP: Replicon-free and markerless methods for genomic insertion of DNAs in phage attachment sites and controlled expression of chromosomal genes in Escherichia coli. Biotechnol Bioeng 2008, 101:985-995.

27. Goh S, Good L: Plasmid selection in Escherichia coli using an endogenous essential gene marker. BMC Biotechnol 2008, 8:61.

28. Haldimann A, Wanner BL: Conditional-replication, integration, excision, and retrieval plasmid-host systems for gene structure-function studies of bacteria. J Bacteriol 2001, 183:6384-6393.

29. Liu JZ, Huang MT, Cui YY, Chen YY: A series of expression plasmids for chromosomal integration and evolution. Chinese patent 201210060042.52012.

30. Zhao Y, Yang J, Qin B, Li Y, Sun Y, Su S, Xian M: Biosynthesis of isoprene in Escherichia coli via methylerythritol phosphate (MEP) pathway. Appl Microbiol Biotechnol 2011, 90:1915-1922.

31. Mickus BE: Transcriptomic and proteomic analysis of lycopene-overproducing Escherichia coli strains, PhD thesis. US: Massachusetts Institute of Technology; 2009

32. Maloy SR, Nunn WD: Genetic regulation of the glyoxylate shunt in Escherichia coli K-12. J Bacteriol 1982, 149:173-180.

33. Sánchez AM, Bennett GN, San K: Novel pathway engineering design of the aerobic center metabolic pathway in Escherichia coli to increase succinate yield and productivity. Metab Eng 2005, 7:229-239.

34. Lee KH, Park JH, Kim TY, Kim HU, Lee SY: Systems metabolic engineering of Escherichia coli for L-threonine production. Mol Sys Biol 2007, 3:149.

35. Kim Y-S, Lee J-H, Kim N-H, Yeom S-J, Kim S-W, Oh D-K: Increase of lycopene production by supplementing auxiliary carbon sources in metabolically engineered Escherichia coli. Appl Microbiol Biotechnol 2011, 90:489-497. 
36. Zahiri HS, Yoon SH, Keasling JD, Lee SH, Kim SW, Yoon SC, Shin YC: Coenzyme $\mathrm{Q}_{10}$ production in recombinant Escherichia coli strains engineered with a heterologous decaprenyl diphosphate synthase gene and foreign mevalonate pathway. Metab Eng 2006, 8:406-416.

37. Wang C, Yoon SH, Jang HJ, Chung YR, Kim JY, Choi ES, Kim SW: Metabolic engineering of Escherichia coli for a-farnesene production. Metab Eng 2011, 13:648-655.

38. Martin VJJ, Pitera DJ, Withers ST, Newman JD, Keasling JD: Engineering a mevalonate pathway in Escherichia coli for production of terpenoids. Nat Biotechnol 2003, 21:796-802.

39. Ajikumar PK, Xiao WH, Tyo KEJ, Wang Y, Simeon F, Leonard E, Mucha O, Phon TH, Pfeifer B, Stephanopoulos G: Isoprenoid pathway optimization for taxol precursor overproduction in Escherichia coli. Science 2010, 330:70-74.

40. Anthony JR, Anthony LC, Farnaz N, Kwon G, Newman JD, Keasling JD: Optimization of the mevalonate-based isoprenoids biosynthetic pathway in Escherichia coli for production of the anti-malarial drug precursor amorpha-4,11-diene. Metab Eng 2009, 11:13-19.

41. Guzman LM, Belin D, Carson MJ, Beckwith J: Tight regulation, modulation, and high-level expression by vectors containing the arabinose $\mathrm{P}_{\mathrm{BAD}}$ promoter. J Bacteriol 1995, 177:4121-4130.

42. Datsenko KA, Wanner BL: One-step inactivation of chromosomal genes in Escherichia coli K-12 using PCR products. Proc Natl Acad Sci USA 2000, 97:6640-6645.

43. Sharan SK, Thomason LC, Kuznetsov SG, Court DL: Recombineering: a homologous recombination-based method of genetic engineering. Nat Protoc 2009, 4:206-223.

doi:10.1186/1472-6750-13-6

Cite this article as: Chen et al: Chromosomal evolution of Escherichia coli for the efficient production of lycopene. BMC Biotechnology 2013 13:6.

\section{Submit your next manuscript to BioMed Central and take full advantage of:}

- Convenient online submission

- Thorough peer review

- No space constraints or color figure charges

- Immediate publication on acceptance

- Inclusion in PubMed, CAS, Scopus and Google Scholar

- Research which is freely available for redistribution 